\title{
O Princípio da Cognoscibilidade e os Qualia
}

\author{
Cícero Antônio Cavalcante Barroso ${ }^{I}$
}

RESUMO: O princípio da cognoscibilidade, formulado sem restriçōes, diz que todos os enunciados verdadeiros são cognoscíveis. O problema é que, com essa formulação, ele está sujeito a muitas objeçôes, pelo que é necessário restringir o princípio. Com tais restriçôes, ele diz apenas que todos os enunciados verdadeiros interessantes em certo sentido são cognoscíveis. Não obstante, este artigo mostra que alguns desses enunciados também são incognoscíveis e, desse modo, evidencia que o princípio da cognoscibilidade, mesmo na sua forma mais restrita, é falso. Os enunciados em questão são enunciados que afirmam ou negam uma identidade de tipo entre qualia de diferentes indivíduos. Ao final, alguns argumentos que podem ser usados para defender o princípio da cognoscibilidade são examinados e refutados.

PALAVRAS-CHAVE: Princípio da cognoscibilidade. Qualia. Princípio da verificação.

\section{INTRODUÇÃo}

O princípio da cognoscibilidade (PC) é um princípio epistêmico que reivindica que todas as verdades são cognoscíveis, no sentido de que, para todo enunciado $\mathrm{P}$, se P é verdadeiro, existe um sujeito $S$ que pode saber que P é verdadeiro em algum tempo. Essa reivindicação é sem dúvida muito ambiciosa, e acarreta consequências indesejadas. De fato, há contraexemplos inegáveis a essa formulação do PC. Uma sugestão natural para tentar salvar o que o princípio tem de mais intuitivo é torná-lo mais moderado. Pode-se argumentar que isso poderia ser feito, se adotássemos uma versão do PC que se limitasse a alegar que toda verdade sobre o mundo empírico é cognoscível.

Essa alegação é de fato muito atraente, pois funciona como um tipo de garantia de que podemos ter acesso epistêmico aos fatos do mundo. A própria prática científica parece depender dessa garantia. Sem ela, abre-se espaço para a existência de fatos misteriosos, fatos que nunca poderemos conhecer. $\mathrm{O}$ que poderia ser mais avesso à nossa visão científica do mundo? Tudo indica, por-

\footnotetext{
${ }^{1}$ Professor adjunto da Universidade Federal do Ceará e pesquisador do Conselho Nacional de Desenvolvimento Científico e Tecnológico (CNPq). Doutor em Filosofia pela Pontifícia Universidade Católica do Rio de Janeiro. Coautor do livro Lógica: Os Jogos da Razão. Coordenador do Grupo de Pesquisa NEFA (Núcleo de Estudos de Filosofia Analítica). E-mail: cicero@lia.ufc.br. Blog: http:// nefa-ufc.blogspot.com.br/
} 
tanto, que essa alegação faz uma reivindicação bastante plausível. Se obtivermos uma versão do $\mathrm{PC}$ que a assevere, podemos manter a esperança de que ele não mais estará sujeito a contraexemplos.

Nas seções seguintes, porém, ficará manifesto que essa esperança é vã. Inicialmente, mostrar-se-á como podemos encontrar uma forma mais restrita do PC, uma forma imune a algumas críticas que foram feitas ao princípio, em sua forma original. Em seguida, será feita uma análise de certos enunciados sobre qualia, a qual evidenciará que eles se qualificam como contraexemplos a essa versão mais restrita do PC. Por fim, serão consideradas algumas tentativas de bloquear essa última crítica à forma restrita do $\mathrm{PC}$ e se verificará que elas também fracassam.

Essa discussão final evidenciando como certos enunciados sobre qualia podem ser usados para invalidar o PC pode ser considerada a contribuição mais original do artigo para o tema. Além disso, ela conduz a reflexóes mais gerais sobre a natureza da experiência consciente e os limites do nosso conhecimento da realidade.

\title{
O PRINCÍPIO DA COGNOSCIBILIDADE E SUAS RESTRIÇÓES
}

No artigo "A Logical Analysis of Some Value Concepts", de 1963, Frederic Fitch apresentou uma prova de que, se existem verdades que ninguém sabe que são verdades, então há verdades incognoscíveis. Destarte, como parece razoável supor que há verdades desconhecidas, a prova de Fitch equivale a uma prova da falsidade do PC. A demonstração pode ser reconstruída da seguinte forma:

\author{
P é uma verdade desconhecida (hipótese) \\ Toda verdade é cognoscível (PC) \\ $\mathrm{Q}=$ "P é uma verdade desconhecida" (def) \\ Q é cognoscível (por PC) \\ É possível saber que Q \\ É possível saber que P é uma verdade desconhecida (pela definição de Q)
}

Mas não é possível saber que P é uma verdade desconhecida, pois se um sujeito $S$ sabe que $P$ é uma verdade, então $P$ não é desconhecida para $S$

Assim, a combinação da hipótese com PC acarreta um absurdo

Com base nesse absurdo, o que podemos fazer é: 
a) Concluir que a hipótese é falsa; ou,

b) Concluir que PC é falso

A alternativa (a) está fora de questão, pelo fato de que $\mathrm{P}$ pode ser qualquer verdade desconhecida. Se concluirmos que a hipótese é falsa, estamos na verdade concluindo que a hipótese é falsa para qualquer $\mathrm{P}$, o que é o mesmo que dizer que não há verdades desconhecidas. Como isso é evidentemente falso, só nos resta a alternativa (b), ou seja, só nos resta concluir que PC é inválido. QED

Embora, prima facie, a demonstração de Fitch pareça sólida, há quem encontre certos problemas nela. No artigo de Berit Brogaard e Joe Salerno para a Stanford Encyclopedia of Philosophy sobre o paradoxo de Fitch, há um relato detalhado de todos os problemas que os críticos apontaram na demonstração e das várias tentativas de evitar seu drástico resultado (BROGAARD; SALERNO, 2010). As críticas e as tentativas são interessantes e dignas de atenção, mas os autores demonstram de forma convincente que elas não são conclusivas. Tanto é assim que mesmo muitos dos simpatizantes do PC ficaram convencidos da prova de Fitch, embora não convencidos de que PC estava irremediavelmente perdido. Esses entusiastas do princípio estimaram que a prova de Fitch não lhe atingia em toda a sua extensão, que ela apenas mostrava que em alguns casos PC não era válido. Eles pensaram então que poderiam, por assim dizer, salvá-lo com uma amputação. Dito de modo claro, eles julgaram que poderiam manter o princípio vivo, impondo-lhe algumas restriçôes.

Se pensarmos nas razões que alguém pode ter para defender PC, essa restrição faz muito sentido. PC é um princípio que estabelece uma conexão entre os enunciados verdadeiros e o nosso conhecimento deles e, ao fazer isso, ele nos assegura que a verdade está ao nosso alcance. Contudo, que tipo de verdade nós realmente buscamos? Que tipo de verdade nos interessa, em primeiro lugar? Quando PC declara que toda verdade é cognoscível, talvez ele esteja indo além do que nós realmente precisamos. Talvez não seja preciso declarar que toda verdade é cognoscível, mas apenas que as verdades que mais necessitamos conhecer são cognoscíveis.

Se tivermos um pouco mais de atençáo, veremos que o que a prova de Fitch mostra é a existência de uma classe de verdades incognoscíveis, a saber, a classe das verdades $Q$ que afirmam que um enunciado P qualquer é uma verdade desconhecida. Tais verdades existem, uma vez que inegavelmente existem verdades desconhecidas. Além disso, tais verdades são incognoscíveis, porque é 
impossível alguém saber que um enunciado P qualquer é uma verdade desconhecida. Agora, o que é importante notar aqui é que essa classe de verdades é muito específica, e isso faz com que a prova de Fitch seja também muito específica. A prova revela que não podemos conhecer verdades do tipo Q, porém, nada diz sobre verdades do tipo P. Dentre esses dois tipos de verdade, qual seria o mais vital para nossos interesses epistêmicos?

Para responder a essa pergunta, pode ser importante recordar a diferença entre linguagem-objeto e metalinguagem. A primeira é a linguagem que usamos quando queremos falar do mundo extralinguístico e de seus componentes (e.g., pessoas, coisas, lugares etc.), e a segunda é a linguagem que usamos para falar de itens linguísticos (enunciados, palavras etc.). Dadas essas definiçôes, é possível concluir que, se conhecêssemos todos os enunciados verdadeiros da linguagem-objeto, saberíamos tudo sobre o mundo extralinguístico, e isso ocorreria mesmo que ignorássemos metade das verdades metalinguísticas. Não parece difícil concordar que nossas demandas epistêmicas mais urgentes estariam satisfeitas, em tal conjuntura.

Agora, se voltarmos a considerar os enunciados do tipo Q, veremos que eles são enunciados metalinguísticos. $\mathrm{O}$ que eles fazem é declarar algo sobre os enunciados do tipo P. Já os enunciados do tipo $\mathrm{P}$ podem muito bem ser enunciados da linguagem-objeto. Se concordarmos que nossa demanda por conhecimento é mais premente com relação ao conhecimento empírico, então a conclusão de que verdades do tipo Q não são cognoscíveis não parecerá tão desastrosa. Talvez possamos viver sem a garantia de podermos conhecer a verdade de certos enunciados metalinguísticos, se conseguirmos manter essa garantia para as verdades da linguagem-objeto. Se for assim, não precisamos dar um escopo de aplicação irrestrito ao PC, podemos tomá-lo com mais moderação. Ao invés de considerá-lo como sendo uma declaraçáo de que toda verdade é cognoscível, podemos tomá-lo em uma versão mais moderada, uma versão na qual ele se limita a declarar que toda verdade da linguagem-objeto é cognoscível².

Suponha então que adotemos essa versão moderada do princípio de cognoscibilidade (chamemo-lo de $\mathrm{PC}_{\mathrm{m}}$ ), ou seja, suponha que $\mathrm{PC}_{\mathrm{m}}$ declare apenas que verdades da linguagem-objeto são todas cognoscíveis. Se analisarmos a prova de Fitch, veremos que ela nem mesmo chega a arranhar a

\footnotetext{
${ }^{2}$ Salerno e Brogaard (2010) mencionam outras restriçóes que foram feitas ao PC, depois da prova de Fitch. Eles as dividem entre semânticas, as quais se baseiam em consideraçóes sobre as estruturas de interpretação que usamos para valorar enunciados epistêmicos e modais, e sintáticas, que buscam limitar o escopo de aplicação de PC a verdades que possuam um tipo interessante de propriedade sintática.
} 
integridade de $\mathrm{PC}_{\mathrm{m}}$, pois ela só demonstra que algumas verdades da metalinguagem são incognoscíveis. Não há dúvida de que pelo menos dessa ameaça o princípio se exime. Porém, será que $\mathrm{PC}_{\mathrm{m}}$ está livre de outros problemas? Aparentemente, não.

Considere o enunciado:

(i) Existe um mundo fora da minha mente

Uma vez que esse enunciado faz uma declaração sobre o mundo extralinguístico, devemos concordar que ele pertence à linguagem-objeto. Ora, se os argumentos dos céticos de todos os tempos merecem algum crédito, temos que admitir que, mesmo que (i) seja verdadeiro, não podemos saber disso e, se é assim, $\mathrm{PC}_{\mathrm{m}}$ está em maus lençóis. É certo que algumas pessoas defendem que a verdade de (i) é cognoscível, mas essa defesa não parece cogente. Moore (1939), por exemplo, tentou provar a existência do mundo exterior, levantando sua mão direita e dizendo "aqui está uma mão", mas esse tipo de argumentação não pode evitar a crítica de que incorre numa petição de princípio. Esse é apenas um de vários exemplos de tentativas fracassadas de afastar as suspeitas filosóficas acerca da existência do mundo exterior. Em vista disso, pode-se dizer que o enunciado (i) realmente cria um problema para nossa versão moderada do princípio da cognoscibilidade. $\mathrm{O}$ que então podemos fazer para salvar $\mathrm{PC}_{\mathrm{m}}$ desse problema? Creio que a única coisa que podemos fazer é restringir o princípio ainda mais.

Para esse propósito, será útil chamar à cena a noção searliana de posição-padrão. Searle (2000) chama de "posiçóes-padrão" aquelas nossas crenças fundamentais que são pressupostas por todas as nossas outras crenças. Ele lista algumas dessas posiçóes-padrão, e a primeira da lista corresponde ao enunciado (i). Enquanto pressuposiçóes, as posiçôes-padrão não admitem prova ou verificação, elas simplesmente são tomadas como concedidas. Nesse sentido, elas são diferentes de opiniôes. Para sabermos que uma opiniāo é verdadeira, precisamos de evidência, porém, as posiçôes-padrão não são admitidas por causa de nenhuma evidência. Isso náo é possível, pois são as posiçóes-padrão que determinam o que conta como evidência para uma opiniấo. Ver que a neve é branca, por exemplo, só conta como evidência para minha opinião de que a neve é branca, porque admitimos posiçóes-padrão que estabelecem que há um mundo externo e que nossos métodos de observação nos dão acesso a ele. Graças a isso, posso saber que a neve é branca. 
Todavia, como posso saber que uma posição-padráo é verdadeira? Pelo que se pode inferir da exposição de Searle, eu não sei, eu apenas aceito que ela é. Essa resposta mostra claramente que $\mathrm{PC}_{\mathrm{m}}$ não deve ser aplicado a enunciados que expressam posiçôes-padrão. De todo modo, aparentemente, é possível salvaguardar ainda um amplo escopo de aplicação para o princípio. Ainda podemos sustentar que todos os enunciados da linguagem-objeto que expressam opiniōes verdadeiras (simples opinióes, não posiçôes-padrão) são cognoscíveis. Assim, definimos uma nova restrição para o princípio da cognoscibilidade, que agora aparece ainda mais moderado do que na versão $\mathrm{PC}_{\mathrm{m}}$.

Não obstante, essa restrição não parece prejudicar muito o princípio. É até bem razoável asseverar que, quando enunciamos o princípio da cognoscibilidade, as verdades que desejamos que ele nos assegure que são cognoscíveis são as verdades de nossas opiniōes, tanto as científicas como as que tratam do nosso cotidiano. Destarte, sugiro que conservemos, pelo menos por enquanto, esse princípio de cognoscibilidade ainda mais moderado (chamemo-lo de $\mathrm{PC}_{\mathrm{m}+}$ ).

Apesar de todo esse labor argumentativo para conservar uma versão defensável do princípio de cognoscibilidade, na próxima seção deste artigo, será argumentado que nem mesmo $\mathrm{PC}_{\mathrm{m}+}$ é válido. Demonstrar-se-á que há uma classe de enunciados os quais expressam opinióes sobre fatos do nosso mundo putativo que são tais que, quando enunciam verdades, enunciam verdades incognoscíveis. A classe de enunciados que Fitch (1963) tentou mostrar que são incognoscíveis seriam incognoscíveis por razões lógicas. Os enunciados que enunciam posiçôes-padrão seriam incognoscíveis por razóes metafísicas ou metodológicas. Os enunciados que serão introduzidos na próxima seção são incognoscíveis por razóes lógico-metafísicas. Não é certo que essas razões sejam mais convincentes do que as outras, mas acredito que uma discussão sobre elas pode contribuir significativamente para nossa compreensão da realidade e dos limites da ciência. Por isso, vale a pena discuti-las.

\section{ENUNCIAdOS TERCEIRIZAdOS E O PROBLEMA QUE ELES CRIAM PARA O PC $\mathrm{M}_{+}$}

Quando um indivíduo percebe, imagina ou sente alguma coisa, há algo para aquele indivíduo que é como ter aquela experiência. Em filosofia da mente, costuma-se pensar que esse algo que dá o caráter de subjetividade às experiências de alguém é um tipo de propriedade, uma propriedade fenomênica. São essas propriedades que costumamos chamar de qualia (plural de quale). Quando uma pessoa percebe uma cor, ela tem um quale, quando sente um cheiro, 
ela tem um quale, quando está alegre, ela tem um quale, quando está com uma coceira, ela tem um quale etc. São os qualia que conferem a uma experiência o seu aspecto distintivo, fazendo com que seja experimentada de uma forma e não de outra. Graças a eles podemos, por exemplo, distinguir a cor vermelha do som de um oboé, o cheiro de café da vontade de ir ao banheiro, o gosto de páprica do êxtase de um orgasmo etc. Além disso, como são propriedades de experiências subjetivas, os qualia só existem enquanto se dá a experiência do indivíduo e só existem para aquele indivíduo. Cada indivíduo só tem acesso aos seus qualia e aos de ninguém mais.

É importante notar que, embora cada quale seja uma propriedade fenomênica singular, é possível dizer que dois qualia são do mesmo tipo. Podemos dizer isso se o indivíduo que os tem os identifica com o mesmo nome ou descrição. Assim, por exemplo, se um indivíduo chama de "azul" tanto o quale que ele tem, quando vê o céu radiante pela manhã, como o quale que ele tem, quando vê os olhos do Frank Sinatra, então é possível dizer que esses qualia são do mesmo tipo.

Identificar tipos de qualia é tão imprescindível para nossa ação no mundo quanto identificar rostos, formas, tipos naturais, eventos etc. Nosso comportamento consciente é aparentemente todo baseado em correlaçóes entre tipos de condiçóes observadas e tipos de açóes possíveis para nós. Por exemplo, uma dessas correlaçóes poderia ser expressa pela asserção: "em caso de perigo, a melhor coisa a fazer é fugir". Está claro que essa asserção só tem alguma efetividade para minha vida, porque eu sei classificar certas condiçóes que observo como condiçóes de perigo e certas açóes que posso fazer como açóes de fuga. As palavras "perigo" e "fugir" indicam tipos nos quais eu encaixo certas coisas e comportamentos. Parece plausível pensar que o elemento qualitativo de qualquer de minhas experiências conscientes também só terá valor para minha vida, se eu puder fazer com ele o mesmo tipo de categorização que eu faço com minhas outras observaçóes. Considere, por exemplo, o enunciado: "se o peixe tem cheiro de amônia, o melhor é não comê-lo". Esse enunciado só tem valor prático, porque eu posso identificar o tipo do cheiro do peixe. Nesse caso, eu posso dizer que o cheiro é de um tipo que eu posso referir com a expressão "cheiro de amônia”. Esse é um caso em que a vinculação de um quale particular a um tipo geral é inegável, mas a verdade é que qualquer quale experienciado deve ser vinculado a um tipo, para que eu possa usá-lo em correlações úteis para a minha vida. 
Agora, tudo isso é perfeitamente factível quando trato de tipificar meus próprios qualia, mas o que acontece se tiver de identificar o tipo dos qualia de outra pessoa? Como foi dito, os qualia são individuais, portanto, tudo o que essa pessoa pode me oferecer como evidência do tipo de quale que ela tem, em certo momento, é a terminologia que ela usa para referi-lo ou descrevê-lo. Contudo, será que isso é suficiente para que eu possa concluir que a pessoa tem um quale deste ou daquele tipo? Suponha, por exemplo, que os indivíduos A e B usam a palavra "azul" para descreverem o quale que têm, quando veem o céu radiante pela manhá. Se você pensar bem, concordará que não se pode, com base nisso, dizer que seus qualia são do mesmo tipo. Mesmo que ambos sejam sinceros, quando dizem que têm a experiência de algo "azul", não há qualquer garantia de que seus qualia são do mesmo tipo. Pode ser que o quale de A seja de um tipo que B chamaria de "vermelho", ou de "molhado". De qualquer forma, mesmo sem haver tal garantia, pode ser que efetivamente o quale de A seja de um tipo que B chamaria de "azul”. Assim, há um sentido que podemos atribuir ao enunciado:

(1) Quando A e B observam o céu radiante pela manhã, seus qualia são do mesmo tipo.

E, da mesma forma, há um sentido neste outro enunciado:

(2) Quando A e B observam o céu radiante pela manhã, seus qualia não são do mesmo tipo.

Os qualia de A e B podem ser do mesmo tipo, porque, se um indivíduo C tivesse as experiências visuais de A e B, esse indivíduo poderia dizer se os qualia que A e B têm, quando observam o céu pela manhã, são do mesmo tipo ou não. Se fossem do mesmo tipo, $\mathrm{C}$ poderia dizer se os qualia pertencem ao tipo que ele chama de "azul", ou a algum outro tipo. Se os qualia fossem de tipos diferentes, ele poderia dizer de cada um se ele pertence ao tipo que ele chama de "azul", ou a algum outro tipo.

É claro que ninguém pode ter as experiências visuais de outra pessoa, mas isso é uma limitação epistêmica dos sujeitos cognoscentes, não um problema dos fatos. Os qualia estão lá perfeitamente distintos para A e B e, como tal, deve-se admitir que é uma questão de fato que eles sejam do mesmo tipo ou não. Se eles são do mesmo tipo, o enunciado (1) é verdadeiro e o (2) é falso; se eles não são do mesmo tipo, o enunciado (2) é verdadeiro e o (1) é falso. 
Vemos, portanto, que pelo menos um dos enunciados é verdadeiro. Temos que admitir, entretanto, que nenhum ser humano é capaz de verificar a verdade de tal enunciado. Para isso, seria preciso que os qualia de A e B fossem de alguma forma transferidos para um mesmo indivíduo e que esse indivíduo tivesse ciência dessa transferência. Como isso não é possível, temos que concluir que ou (1) ou (2) é uma verdade incognoscível.

Pelas mesmas razóes apresentadas acima, podemos concluir de modo geral que todo enunciado verdadeiro que afirma ou nega uma identidade de tipo entre qualia de indivíduos diferentes é incognoscível. Para que tais verdades fossem conhecidas, seria preciso que alguém tivesse acesso aos qualia desses indivíduos, e isso, dado o nosso entendimento do que seja um quale, é impossível. Assim, concluímos que toda uma classe de enunciados é incognoscível. Esses enunciados são obviamente enunciados da linguagem-objeto e de forma alguma podem ser vistos como enunciados que expressam posiçóes-padrão. Pode-se concluir entấo que eles constituem um contraexemplo a $\mathrm{PC}_{\mathrm{m}+}{ }^{3}$

Em todo caso, alguém pode ter a sensação de que a classe de enunciados supracitada é muito restrita e, por isso mesmo, o impacto de sua existência sobre $\mathrm{PC}_{\mathrm{m}+}$ seria desprezível. Acontece que (1) e (2) exemplificam só aqueles enunciados que expressam a identidade entre tipos de qualia de maneira mais explícita. Não obstante, é possível identificar enunciados que fazem isso de forma menos óbvia.

Suponha, por exemplo, que você estivesse com A quando, ao olhar para o céu, ele dissesse: "o céu está muito azul hoje". Com esse enunciado, A estará fazendo um relato de primeira pessoa sobre seu quale de cor. Para A, o tipo a que pertence esse quale fica evidente em sua experiência, por isso, a verdade de seu enunciado lhe é perfeitamente conhecida. Acontece que, depois de ouvir a declaração de $A$, você também poderá fazer um relato indireto sobre a experiência de $\mathrm{A}$, só que, nesse caso, o relato será de terceira pessoa. Você poderá fazer esse relato dizendo: "A teve uma experiência vívida de azul, ao olhar para o céu pela manhâ”.

\footnotetext{
${ }^{3}$ Note que essa conclusão, como também a conclusão sobre enunciados terceirizados que será apresentada em seguida, depende de assumirmos que temos qualia e que não temos acesso aos qualia dos outros. Até agora, isso foi assumido unicamente com base em uma intuiçáo de senso comum, no entanto, existem objeçóes a essas presunçóes. Na seçáo seguinte, lidaremos com essas objeçóes.
} 
Mas aqui surge uma dúvida crucial: o que você significa por "azul”? A minha sugestão é de que você chama de "azul" aquilo que você conhece como "azul", isto é, o tipo que comporta seus qualia de "azul", não pode ser outra coisa. Assim, seu enunciado de terceira pessoa pode ser parafraseado da seguinte forma: "A teve uma experiência do tipo que eu chamo de 'experiência vívida de azul', ao olhar para o céu pela manhä". Nessa paráfrase, fica claro que seu enunciado afirma que há uma identidade de tipo entre a experiência de $\mathrm{A}$ e algumas de suas próprias experiências. Todavia, se é assim, seu enunciado não é diferente dos enunciados exemplificados em (1) e (2), e, da mesma forma que eles, sua verdade ou falsidade não pode ser realmente conhecida por nenhum ser humano. Nesse sentido, seu enunciado é igualmente um contraexemplo a $\mathrm{PC}_{\mathrm{m}+}$.

Ocorre que essa não é uma característica exclusiva do seu enunciado. Não é difícil nos convencermos de que ele é apenas um caso particular em um oceano de exemplos. De fato, há incontáveis enunciados como o seu - enunciados de terceira pessoa que resultam da observação de um relato de primeira pessoa sobre qualia. Na falta de um nome melhor, vou chamá-los de "enunciados terceirizados". O que se pode perceber é que, pela mesma estrutura de raciocínio que evidencia a incognoscibilidade do seu enunciado, pode-se mostrar que todo enunciado terceirizado é incognoscível.

É importante notar, porém, que o que estou chamando de "enunciado terceirizado" é uma asserção sobre o fato subjetivo descrito por um enunciado de primeira pessoa (enunciado da linguagem-objeto), e não um simples relato de um enunciado de primeira pessoa (enunciado metalinguístico). Assim, se em vez de dizer "A teve uma experiência vívida de azul, ao olhar para o céu pela manhâ", você dissesse "A relatou isto pela manhã: 'o céu está muito azul hoje”, seu enunciado não seria terceirizado, pois você estaria falando sobre as palavras que você ouviu, e náo sobre a experiência sensória de A. Se você usasse o discurso direto, ou seja, se você dissesse "A relatou pela manhã que o céu estava muito azul", a condição do seu enunciado seria um pouco mais controversa, pois alguém poderia interpretá-lo como uma asserção sobre a experiência de A. Não obstante, creio ser mais razoável admitir que o enunciado não é nada mais do que uma paráfrase daquele que usa o discurso direto, de modo que também é um enunciado metalinguístico e, como tal, não pode ser terceirizado.

Por fim, é preciso mencionar que a incognoscibilidade dos enunciados terceirizados não é sem consequência para a prática científica. Repare que a intuição por trás do princípio da cognoscibilidade é de que a verdade dos enunciados que descrevem os fatos corriqueiros do mundo deve ser cognoscí- 
vel. Com isso, ele tenta garantir a possibilidade de uma explicação científica desses fatos. $\mathrm{O}$ que vemos, no entanto, é que $\mathrm{PC}_{\mathrm{m}+}$ não consegue garantir a cognoscibilidade de enunciados terceirizados, os quais seriam de grande ajuda para descrever fatos corriqueiros do mundo (e.g., o fato de alguém ver o azul do céu). Em razão disso, o labor explanatório da ciência se vê estorvado, quando tenta se utilizar de enunciados terceirizados, recurso que pode ser especialmente tentador nos estudos da consciência. Isso ficará manifesto nas consideraçốes finais.

\section{PossíveIS ARgumentos EM FAVOR Do $\mathrm{PC}_{\mathrm{M}+}$}

Posso pensar em três argumentos que poderiam ser usados aqui para defender $\mathrm{PC}_{\mathrm{m}+}$. O primeiro, que entendo como o mais extravagante, é o argumento de que não existem qualia. Considero esse argumento extravagante, porque me parece que, se alguém nega que existem qualia, nega simultaneamente que vê cores, que ouve sons, que sente gostos, que sente dores etc. Se alguém nega essas coisas e não admite que é um robô, ou um zumbi, ou um vegetal, ou um louco, então só posso dizer que sua negação é extravagante, e isso é o mínimo que posso dizer. Em todo caso, alegaçôes desse tipo são feitas por filósofos conhecidos como eliminativistas. Elas aparecem, por exemplo, em Dennett (1988, 1991, 1992 etc.), em relação a qualia de todos os tipos, e em Tye (1995) e Harmann (1990), em relação aos qualia visuais. Os argumentos apresentados para justificar essas alegaçôes são variados e sutis, e bastante dignos de atenção, mas teria que fazer uma digressão imensa para tratá-los aqui, e isso foge ao meu propósito.

Em vez disso, quero apenas sublinhar que a tese de que os qualia não existem equivale à tese de que nossa consciência fenomênica, ou seja, nossos estados conscientes qualitativos não existem. Alguém poderia argumentar que, se esse é o real significado da negação dos qualia, então tal tese não pode ser verdadeira. A nossa percepção, a nossa introspecção e várias das nossas outras funçôes cognitivas provariam que ela é falsa. O problema é que os eliminativistas também bloqueiam o caminho para essa conclusão. Eles afirmam que nem nossos sentidos nem qualquer de nossos métodos de aquisição de informação provam que somos fenomenicamente conscientes. O nosso cérebro nos faz acreditar que temos uma consciência fenomênica, mas a verdade é que não temos. Isso parece plausível? Os argumentos dos eliminativistas buscam justamente conferir plausibilidade às suas teses. Como já foi dito, esses argumentos 
não serão analisados aqui, não obstante, é bom observar que, se aceitarmos a conclusão que eles tentam fundamentar, teremos que aceitar que todo nosso mundo fenomênico é uma ilusão, e uma ilusão das mais estranhas, pois não se trata aqui de tomar a aparência pela realidade. Não pode ser isso, já que sem qualia náo existe aparência.

Fica, portanto, sem resposta esse argumento que visa a salvar $\mathrm{PC}_{\mathrm{m}_{+}} \mathrm{com}$ base na negação dos qualia. Destarte, vou manter apenas uma objeção condicional a $\mathrm{PC}_{\mathrm{m}+}$, a saber, se existem qualia, $\mathrm{PC}_{\mathrm{m}+}$ é falso.

Um segundo argumento em prol de $\mathrm{PC}_{\mathrm{m}+}$ seria o de que podemos conhecer a verdade de enunciados como (1) e (2), se assumimos a tese de que os mesmos tipos de eventos neurofisiológicos produzem os mesmos tipos de qualia. Assim, embora não possamos experimentar os qualia de A e B, podemos nos basear em sua atividade neurofisiológica para concluir se eles têm ou não qualia do mesmo tipo. Se eles têm o mesmo padrão de atividade cerebral, eles têm qualia do mesmo tipo, de outra forma, têm qualia de tipos distintos. Uma vez que podemos, em princípio, saber se duas pessoas têm o mesmo padrão de atividade cerebral, poderíamos igualmente, em princípio, saber se elas têm qualia do mesmo tipo.

O problema com esse argumento é que a tese que ele sugere que deveríamos assumir não parece empiricamente bem fundada. Como podemos saber, em geral, que os mesmos tipos de eventos neurofisiológicos produzem os mesmos tipos de qualia? Creio que há base empírica suficiente para justificar a tese de que as mesmas causas objetivas produzem os mesmos efeitos objetivos, contudo, não há absolutamente nenhum caso que possamos observar e usar para corroborar a tese de que as mesmas causas objetivas produzem sempre os mesmos qualia em indivíduos diferentes. Para justificar tal tese, precisaríamos dispor de casos nos quais observássemos que dois indivíduos têm os mesmos qualia, quando apresentam o mesmo padrão de atividade cerebral. Mas é exatamente esse tipo de observação que não podemos fazer. Podemos até em princípio observar os eventos neurofisiológicos que ocorrem em dois indivíduos e verificar se eles têm o mesmo padrão, entretanto, no que diz respeito aos qualia que esses indivíduos têm, não podemos fazer nenhuma observação. $\mathrm{O}$ máximo que podemos saber sobre esses qualia é o que os próprios indivíduos venham a relatar sobre eles, porém, isso, como vimos, não pode nos dar nenhum conhecimento real dos qualia. Sydney Shoemaker deixou isso evidente, em seu artigo "The Inverted Spectrum”, de 1982. Dessa maneira, podemos 
concluir que o segundo argumento pró- $\mathrm{PC}_{\mathrm{m}+}$ falha, porque não temos nenhuma razão sólida para assumir a tese que ele sugere que assumamos.

$\mathrm{O}$ terceiro argumento pró- $\mathrm{PC}_{\mathrm{m}+}$ que posso imaginar se apoia no princípio da verificação para declarar que os enunciados os quais asseveram uma identidade de tipo entre qualia de diferentes indivíduos não são nem verdadeiros nem falsos. Segundo o princípio da verificação, um enunciado não-analítico (supostamente empírico) só tem sentido e, portanto, um valor de verdade, se existir um modo de verificá-lo, pelo menos em princípio ${ }^{4}$. Como enunciados da estirpe de (1) e (2) não são analíticos e não podem ser verificados, eles não seriam nem verdadeiros nem falsos. Destarte, não poderiam tampouco ser verdades incognoscíveis. Nenhum deles poderia ser usado como um contraexemplo para $\mathrm{PC}_{\mathrm{m}+}$, o que se aplicaria também aos enunciados terceirizados.

É importante notar que o princípio da verificação, tal como é formulado acima, estabelece mais do que uma regra de significatividade para os enunciados não analíticos: ele estabelece algo sobre a própria constituição da realidade. Se admitimos que são os fatos descritos pelos enunciados empíricos que os tornam verdadeiros ou falsos, entâo temos que concordar que um enunciado que não é nem verdadeiro nem falso não descreve fato nenhum. Em outras palavras, enunciados que não podem ser verificados simplesmente não descrevem fatos. É exatamente por isso que eles não podem ser verificados. Dessa forma, o princípio da verificação estabelece que a realidade é constituída apenas pelos fatos descritos corretamente por enunciados verificáveis. Ele estabelece que fatos epistemicamente inacessíveis não existem ${ }^{5}$. Como os enunciados que asseveram uma identidade de tipo entre qualia de diferentes indivíduos não são verificáveis, a consequência que temos é que eles não descrevem fatos de nenhum tipo.

Qualquer objeção a esse terceiro argumento deve atacar em primeiro lugar o princípio de verificação. É o que vou fazer doravante. Primeiramente,

\footnotetext{
${ }^{4}$ Embora o princípio da verificação já seja de certa forma sugerido no manifesto dos neopositivistas ("A Concepção Científica do Mundo. O Círculo de Viena”, de Neurath, Carnap e Hahn, 1929), é o filósofo britânico Alfred Ayer que, nas duas ediçōes de seu livro Language, Truth and Logic (1936, 1946), vai apresentá-lo de forma explícita e formalizada. Após descobrir um problema em sua primeira formulação do princípio (em 1936), Ayer lhe dá uma nova formulação (em 1946). Nessa nova formulação, ele distingue entre enunciados diretamente verificáveis e indiretamente verificáveis, mas a formulação que dou do princípio de verificação tenta sintetizar o que há de comum nos dois casos. Há também uma formulação mais recente do princípio, proposta por Crispim Wright, mas considero que minha apresentação informal do princípio é igualmente coerente com essa formulação (WRIGHT, 1989).

${ }^{5}$ Considero que um fato é epistemicamente acessível, se ele é acessível a algum método de observação.
} 
vou fazer uma crítica específica à aplicação do princípio na análise dos enunciados sobre qualia que tenho examinado neste artigo. Depois, vou fazer uma crítica mais geral ${ }^{6}$.

Em primeiro lugar, é preciso dizer que não parece nada razoável afirmar que nem (1) nem (2) descreve um fato. Parece evidente que a verdade ou falsidade desses enunciados depende unicamente dos fatos que eles pretendem descrever. Como foi mencionado anteriormente, os fatos em questão são muito bem determinados, ou os qualia de A e B são do mesmo tipo ou são de tipos diferentes. Não há como duvidar de que essa é uma questão de fato. Nossa incapacidade de verificar os fatos náo a afeta. Ou os fatos determinam que o enunciado (1) é verdadeiro e (2) é falso, ou o contrário. Não há uma terceira alternativa.

Parece muito intuitivo afirmar que há um fato no mundo que consiste em A ter um certo quale, quando vê o céu radiante pela manhã, e que existe outro fato no mundo que consiste em B ter um certo quale, quando vê o céu radiante pela manhã. Ora, se dois fatos têm uma identidade de tipo, isso é um fato, se não têm, isso é um fato do mesmo jeito. Devemos concluir, portanto, que, quer os qualia de A e B sejam do mesmo tipo, quer não sejam, temos um fato, e esse fato não é observável. A situação aqui é semelhante à seguinte: existe algo que é ser um morcego e existe algo que é ser uma tartaruga marinha ${ }^{7}$. Posto isso, podemos supor ou que a experiência de ser um morcego é do mesmo tipo da experiência de ser uma tartaruga marinha ou que é de um tipo diferente. Se o primeiro caso se dá, temos um fato, e temos igualmente um fato, se o segundo caso se dá. Seja como for, em qualquer dos casos, temos um fato não observável. Tanto nessa situação como na situação envolvendo os enunciados (1) e (2), a evidência de que estamos lidando com fatos inobserváveis é muito relevante para ser ignorada. Não dá para negar que há algum fato sendo descrito por (1) ou (2).

Agora, vamos à crítica mais geral.

\footnotetext{
${ }^{6}$ Há várias críticas célebres ao princípio de verificação formulado por Ayer, tanto em sua primeira versão como na segunda. Uma das mais contundentes é feita por Alonzo Church, em seu review de Language, Truth, and Logic, publicado no Journal of Symbolic Logic, em 1949. Church apresenta um argumento para mostrar que, dada a última formulação de Ayer do princípio de verificação, qualquer enunciado é verificável.

${ }^{7}$ Aqui há uma óbvia referência à tese de Nagel sobre o caráter subjetivo da experiência consciente, apresentada em seu clássico artigo "What is it like to be a bat?", de 1974.
} 
Há várias críticas ao princípio de verificação, e não é meu propósito aqui reeditar ou reexaminar essas críticas. Meu propósito é simplesmente refletir sobre as consequências ontológicas do princípio. É razoável o que ele estabelece a respeito dos fatos constituintes da realidade? Como é possível que um simples princípio filosófico estabeleça o que existe e o que não existe? Qual peso pode haver na afirmação de que não existem fatos epistemicamente inacessíveis?

Aqui, em minha opinião, tocamos nas próprias bases de sustentação do princípio da cognoscibilidade. Bem entendido, PC pode ser visto como um corolário do princípio de verificação. Acredita-se que não existem verdades incognoscíveis, porque se acredita que não existem verdades não verificáveis, porque se acredita que o mundo é todo epistemicamente acessível aos métodos de observaçáo disponíveis para o ser humano. Eu entendo que o apego a essa crença foi a principal força propulsora do esforço que geraçóes de filósofos empreenderam para salvar PC. Essa crença motivou, no passado, as restriçóes que se fizeram ao PC, e motiva hoje a postura eliminativista de muitos filósofos da mente. O heterofenomenalismo de Dennett, por exemplo, se apoia claramente em premissas verificacionistas ${ }^{8}$.

Todavia, por que a crença na acessibilidade epistêmica do mundo é táo estimada por alguns filósofos? Parece-me que essa crença serve como uma salvaguarda para a ciência. A realidade deve ser cientificamente explicável, ela deve caber dentro do campo de visão da ciência. Se houvesse partes da realidade que não pudessem ser explicadas cientificamente, ou se abriria espaço para explicaçóes não científicas dessas partes, ou simplesmente teríamos que admitir que, na composição da realidade, há fatos inexplicáveis e, pior do que isso, fatos inobserváveis. As duas alternativas, é preciso confessar, são extremamente incômodas.

Creio que esse incômodo é compreensível, mas não acho que ele seja suficiente para justificar a crença na acessibilidade epistêmica da totalidade do mundo, se temos boas razóes para duvidar da mesma. Penso que os enunciados que asseveram uma identidade de tipo entre qualia de indivíduos diferentes nos mostram que há tais razóes. Se há um fenômeno que só A pode observar e há outro fenômeno que só $\mathrm{B}$ pode observar, então existe um fato que consiste

\footnotetext{
${ }^{8}$ Em resposta a uma provocação de Rorty, Dennett admite que é um verificacionista, mas ressalta que é um verificacionista urbano e não rural. Ele não explica a diferença, mas é plausível pensar que ela equivale à diferença entre um verificacionista esclarecido (que se apoia em bons argumentos) e um verificacionista ingênuo (DENNETT, 1991, p. 461).
} 
na identidade ou na não identidade de tipo desses dois fenômenos. Esse fato, contudo, ninguém pode observar. Desse modo, somos forçados a admitir que a realidade comporta fatos não observáveis. Não parece razoável negar essa conclusão simplesmente porque ela nos incomoda.

$\mathrm{Na}$ verdade, pensando em termos mais amplos, parece uma birra infantil que alguém não aceite que nosso acesso epistêmico à realidade seja limitado. Por que a realidade deveria se ajustar à nossa capacidade de conhecê-la? Sinceramente, não vejo nenhuma razão para isso acontecer. A realidade já estava por aí muito antes de nós. Nossos sentidos e habilidades cognitivas se desenvolveram, ao se confrontarem com essa realidade pré-existente, foram eles que tiveram de se ajustar àquilo que encontraram. Não é aceitável que agora venhamos inverter as coisas, definindo a realidade como aquilo que podemos conhecer.

\section{ConsideraçóEs FINAIS}

Tendo examinado as objeções da seção anterior, e uma vez que elas se mostraram pouco convincentes, devo concluir, pelo menos na falta de outras objeções mais pertinentes, que é legítimo concluir que todo enunciado verdadeiro que afirma ou nega uma identidade de tipo entre qualia de indivíduos diferentes é incognoscível. Dessa forma, também é legítimo concluir que, mesmo em sua versão mais fraca, o princípio da cognoscibilidade é falso.

Não seria o caso de se propor mais uma restrição para o princípio da cognoscibilidade? Creio que chegamos a um ponto em que uma nova restrição se mostraria demasiadamente forçada. O que poderíamos dizer? Que o princípio náo se aplica a certos enunciados da metalinguagem, nem a enunciados que expressam posiçóes-padrão, nem a certos enunciados sobre qualia, mas se aplica a todos os outros enunciados? Minha impressão é de que tal restrição seria completamente artificial. O que a versão original de $\mathrm{PC}$ tinha de mais significativo era sua pretensão de dizer algo sobre a realidade, de nos dar uma garantia de que nenhum aspecto da realidade estava vedado ao conhecimento humano. Entretanto, diante das razóes apresentadas nos parágrafos anteriores, essa pretensão não pode mais se manter. $\mathrm{Na}$ minha avaliação, um princípio que precisa ser emendado a cada novo contraexemplo que surge, em certo ponto, perde completamente a credibilidade, pois fica claro que esses ajustes são totalmente ad hoc. Nesse ponto, não vale mais a pena tentar torná-lo mais moderado. Uma pessoa pode tentar evitar os efeitos nocivos do álcool, bebendo com moderação. Se ela continuar sentindo esses efeitos, pode tentar beber 
com mais moderação ainda. Porém, se mesmo assim ela continuar se sentindo mal, é melhor que pare totalmente de ingerir bebidas alcoólicas. Mutatis mutandis, uma vez que foi constatado que até $\mathrm{PC}_{\mathrm{m}+}$ é sujeito a contraexemplos, acredito que é melhor abandonar de vez o recurso a restrições e reconhecer que o princípio da cognoscibilidade é simplesmente inválido.

A pensar bem, não há nada de nefasto em reconhecer isso. Pelo contrário, esse reconhecimento nos alerta para a necessidade de evitar que possíveis verdades incognoscíveis sejam introduzidas em nossas explicaçóes científicas. Obviamente, queremos que nossas teorias científicas incrementem o nosso conhecimento, e elas não poderão fazê-lo se recorrerem a verdades incognoscíveis. Pode-se desde já perceber que é preciso ter um especial cuidado com nossas teorias da consciência.

É sabido que relatos de primeira pessoa são hoje amplamente admitidos na pesquisa acerca dos NCC ("Neural Correlates of Consciousness"), da imagética mental, da dinâmica das emoções etc. (SCHWITZGEBEL, 2010). Dito de modo simplificado, o que ocorre nessas pesquisas é que as pessoas relatam o que experienciam, e esses relatos são correlacionados com os dados neurológicos, comportamentais e ambientais, de acordo com certas hipóteses de trabalho. Ao descrever o seu processo de pesquisa, o pesquisador deve ser muito criterioso com os enunciados que produzirá. Se levarmos em conta o que foi exposto nas páginas anteriores, teremos que concordar que tudo o que ele pode fazer é emitir enunciados metalinguísticos, enunciados do tipo “o sujeito A relatou que...”, "o paciente B reportou que..." etc. Se ele se referir às experiências dos sujeitos estudados, em vez de aludir aos seus relatos, ele estará fazendo enunciados terceirizados. Ora, uma vez que tais enunciados são incognoscíveis, não é admissível que eles façam parte de uma teoria científica.

Sendo assim, o que constatamos é que qualquer teoria científica $T$ que tente explicar um fenômeno consciente $\mathrm{F}$, na medida em que for baseada em relatos de primeira pessoa, não poderá falar de $\mathrm{F}$, mas apenas de relatos sobre $\mathrm{F}$, das condiçôes em que esses relatos são feitos, dos eventos físicos observados concomitantemente aos relatos, e de coisas dessa natureza.

\section{Agradecimentos}

Agradeço aos membros do grupo de pesquisa NEFA pelas discussóes que ensejaram muitas das ideias deste artigo. Agradeço também à Fundação 
Cearense de Apoio ao Desenvolvimento Científico e Tecnológico (FUNCAP) e ao Conselho Nacional de Desenvolvimento Científico e Tecnológico (CNPq) pelo suporte a minha pesquisa.

BARROSO, Cícero Antônio Cavalcante. The Knowability Principle and the Qualia. Trans/ Form/Açāo, Marília, v. 37, n. 2, p. 91-110, Maio/Ago., 2014.

\begin{abstract}
The knowability principle, formulated without restrictions, asserts that all true statements are knowable. The problem is that it is subject to many objections in this formulation, and therfore it is necessary to restrict the principle. This article shows that even under these restrictions some true statements are also unknowable, and thus shows that the knowability principle, even in its most restricted form, is false. The statements in question are statements that affirm or deny a type identity between qualia of different individuals. Finally, some arguments that can be used to defend the knowability principle are examined and refuted.
\end{abstract}

KEYWORDS: Knowability principle. Qualia. Verification principle.

\title{
REFERÊNCIAS
}

AYER, A. Language, truth and logic. Oxford: Dover Publications, 1952.

. Language, truth and logic. 2.ed. London: Victor Gollancz, 1946. Review by: CHURCH, A. The Journal of Symbolic Logic, v. 14, n. 1, p. 52-53, mar. 1949.

BROGAARD, B.; SALERNO, J. Fitch's paradox of knowability. In: ZALTA, Edward N. (Ed.). Stanford encyclopedia of philosophy (SEP), 2009. Disponível em: <http://plato.stanford.edu/entries/ fitch-paradox>. Acesso em: 15 mar. 2012.

CHALMERS, D. How can we construct a science of consciousness? In: GAZZANIGA, M. (Ed.). The cognitive neurosciences. 3.ed. Cambridge, MA: MIT Press, 2004.

CHURCHLAND, P. Matéria e consciência: uma introdução contemporânea à filosofia da mente. São Paulo: Editora UNESP, 2004.

CRANE, T. The origins of qualia. In CRANE, T.; PATTERSON, S. (Eds.). The History of the mind-body problem. London: Routledge, 2000.

DENNETT, D. Quining Qualia. In: MARCEL, A. J.; BISIACH, E. (Eds.). Consciousness in contemporary science. Oxford: Oxford University Press, 1988.

DENNETT, D. Consciousness explained. Boston: Little, Brown \& Co, 1991.

DENNETT, D.; KINSBOURNE, M. Time and the observer: the where and when of consciousness in the brain. Behavioral and Brain Sciences, v. 15, p.183-247, 1992.

FITCH, F. A logical analysis of some value concepts. The Journal of Symbolic Logic, v. 28, n. 2, p. 135-142, June, 1963. 
GOMES, N. G. Neopositivismo, metafísica, religião e política. In: IMAGUIRE, G.; ALMEIDA, C.; OLIVEIRA, M. (Orgs.). Metafísica contemporânea. Petrópolis: Vozes, 2007.

HARMAN, G. The Intrinsic quality of experience. In: TOMBERLIN, J. (Ed.). Action theory and philosophy of mind. Atascadero, CA: Ridgeview Publishing Co, 1990. (Philosophical Perspectives, 4)

JACKSON, F. Epiphenomenal qualia. The Philosophical Quarterly, v. 32, n. 127, p. $127-$ 136, Apr. 1982.

NAGEL, T. What is it like to be a bat? The Philosophical Review, v. 83, n. 4, p. 435-450, Oct. 1974.

SCHWITZGEBEL, E. Introspection. In: ZALTA, E. N. (Ed.). The Stanford encyclopedia of philosophy (SEP), 2010. Disponível em: <http://plato.stanford.edu/ archives/fall2010/ entries/introspection/>. Acesso em: 15 jul. 2012.

SEARLE, J. Mind, language and society. New York: Basic Books, 2000.

SHOEMAKER, S. The Inverted spectrum. The Journal of Philosophy, v. 79, n. 7, p. $357-$ 381, 1982.

TYE, M. Ten problems about consciousness. Cambridge, MA: MIT Press, 1995.

WRIGHT, C. The Verification Principle: Another Puncture - Another Patch. Mind, v. 98, n. 392, p. 611-622, Oct. 1989.

Recebido em: 19/11/13

Aceito em: $15 / 01 / 14$ 
BARROSO, C. A. C. 